\title{
An Evaluation System of Modern IT Industry Procurement Logistics
}

\section{Service Provider}

\author{
Xin $\mathrm{Li}^{* 1,}$ a , Xiaoning Zhu ${ }^{1, \mathrm{~b}}$, Yanjing $\mathrm{Li}^{1, \mathrm{c}}$ \\ ${ }^{1}$ School of Traffic and Transportation, Beijing Jiaotong University, Beijing, China

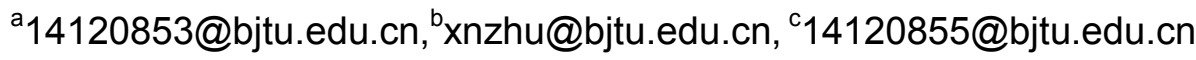

Keywords: IT industry; Purchasing logistics; Service selection

\begin{abstract}
In this paper, combing the IT industry, procurement, logistics service providers choose on the basis of theory, combined with the characteristics of Purchasing and Logistics IT industry, IT industry index system established procurement logistics service providers from the business level, the level of resources, service level, the level of cooperation and information level five indicators were analyzed using evaluation and selection of IT industry procurement logistics service providers in the C2R DEA models. The research enterprise customers how to evaluate logistics service providers choose to provide a theoretical basis and tools, but also for the management of logistics service providers offer some ideas and specific practices .
\end{abstract}

\section{Introduction}

IT is meant to include the modern computer, network communications information technology areas. China as the world's manufacturing plants, are also increasingly foster the growth of a large number of IT companies, such as Lenovo, Huawei Technologies Co. Tencent Holdings Limited. IT industry, especially the rapid development of computers, communications equipment manufacturing company attaches importance to the urgent need for procurement logistics, in order to cut production costs and improve the competitiveness of enterprises.

Researches proved that cooperation with third-party logistics company for enterprises, especially small and medium enterprises in the development stage, can help companies reduce production costs, reducing provisioning of fixed assets and to improve capital turnover, while logistics service providers specialization can also help enterprises to improve the quality of services, and thus enhance the corporate image. But the logistics service provider selection is a complex issue, in addition to be able to meet the business of logistics services, in line with the business development strategy, but also the cultural fit, higher level of information. So for the period of rapid development in the IT industry, the choice of the appropriate procurement logistics service providers is an extremely important issue.

\section{The challenges that Modern IT sectors are facing with}

Challenges of the modern IT industry procurement logistics service providers face is multifaceted, it may come from their own suppliers, as well as from third-party logistics company or clients.

IT industry is a high degree of information integration industry, so the degree of information technology IT industry's ability and market leader in the market is one of sync even reflect the competitiveness of enterprises, for the procurement of logistics service provider selection depends 
on supply and demand of raw materials business situation and supplier prices and supply speed. Platform construction business is facing challenges of modern manufacturing enterprises, the concept of vendor management and ERP systems into the country not long, whether it is software, services, features or applications are to be improved.

Procurement is the source of enterprise production and business activities, and this source also closely dependent on the supplier, the supplier profit-driven phenomenon is obvious, therefore essential to establish a stable and harmonious supplier relationships. This is also the starting point for selecting the IT industry procurement logistics service providers.

IT industry is a complex and highly competitive industry, so the logistics service provider selection, in addition to ensure the timely and efficient logistics services provided outside, but also be able to provide targeted and personalized logistics services. As companies focus on core competencies, the way business is, the allocation of resources are undergoing change. Outsourcing of non-core business model makes the whole process of circulation of goods, many steps are dependent on participation in third-party logistics enterprises, rely on their advanced technology and means to achieve operational logistics activities. So choose a mature logistics service providers involved in the supply chain management is an important issue.

Customer service is the object of the enterprise. Increasing customer logistics service provider for the synchronization requirements prompted the rate of the overall operation of logistics enterprises to enhance and make the whole process of logistics to increase the degree of influence by users lead the IT industry procurement logistics service provider selection uncertainty.

\section{Analysis of factors influencing IT industry procurement logistics service provider selection}

For the IT industry, procurement logistics service providers who choose to be affected by many factors, including macro factors and micro factors.

\section{Macro factors}

Macro factors are mainly government policies, domestic and international market conditions, it is the dominant factor in commodity markets, government policy is a relatively broad concept, monetary policy, fiscal policy, industrial policy, regulatory policy together constitute the national policy, in every below correspond to a policy there are many segments of factors, choose the model difficult to quantify, the qualitative part of the analysis are needed in the IT industry, procurement, logistics service providers.

According to the National Bureau of Statistics, "2013 Statistical Bulletin" shows that in 2013 China's tertiary industry to GDP ratio improved significantly, reaching $46.1 \%$. With China's economic restructuring, the future of the IT industry to lead the high-tech industry will continue to develop, for the country's economic development and building blocks. State "'" Twelfth Five-Year "Plan" stressed vigorously develop modern logistics industry, logistics, as one industry restructuring and revitalization plan of ten industrial revitalization plan, during which the system construction, development, infrastructure, the main products of professional logistics many aspects of the geographical area of development, management and technology, will maintain a sustained and healthy development and play an important role. Logistics service providers in recent years has undergone major changes, third-party logistics maturing, fourth party logistics is also developing steadily. Therefore, whether the government or foreign policy in the market situation, IT industry and logistics service providers are in fact rising in the development stage, which will also be the creation of mutual cooperation between the two more opportunities. 
Table 1 Analysis on macro factors

\begin{tabular}{|c|c|c|c|}
\hline \multirow{6}{*}{$\begin{array}{l}\text { Macro } \\
\text { factors }\end{array}$} & \multirow{4}{*}{$\begin{array}{l}\text { Government } \\
\text { policies }\end{array}$} & $\begin{array}{l}\text { Monetary } \\
\text { Policy }\end{array}$ & Interest rates, exchange rates, deposit reserve ratio \\
\hline & & Fiscal policy & Taxes, debt, national budget \\
\hline & & $\begin{array}{l}\text { Industrial } \\
\text { Policy }\end{array}$ & Industrial planning, industry input and support \\
\hline & & $\begin{array}{l}\text { Regulatory } \\
\text { policy }\end{array}$ & $\begin{array}{l}\text { Laws and regulations, such as the macro-control and } \\
\text { guidance of public opinion }\end{array}$ \\
\hline & \multirow{2}{*}{$\begin{array}{l}\text { Domestic and } \\
\text { international } \\
\text { market } \\
\text { conditions }\end{array}$} & $\begin{array}{l}\text { Domestic } \\
\text { market } \\
\text { conditions }\end{array}$ & \multirow{2}{*}{$\begin{array}{l}\text { Supply and demand situation, trends and the } \\
\text { competitive environment }\end{array}$} \\
\hline & & $\begin{array}{l}\text { International } \\
\text { market } \\
\text { conditions }\end{array}$ & \\
\hline
\end{tabular}

Macroeconomic factors is a collection of environmental factors in the market, and it is for business operations and development has played a role in the coordination and guidance for the IT industry, procurement, logistics service providers choose this issue, the macro factors in the specific implementation may not be evident out but penetrated into all aspects of selecting the reference standard, the evaluation system will be re-possession.

\section{Micro factors}

For IT manufacturing enterprises, micro factors that affect internal and external factors are divided into two categories, internal factors are mainly the management level, culture, technical capabilities and business strategies, external factors are from consumers demand and supply levels vendors, corporate clients and profit sources are consumers, and consumer price expectations, quality, timeliness and other services and the individual needs of the enterprise logistics service providers choose varying degrees of impact, promote enterprise and third-party service companies; suppliers reflected in the level of business skills and cultural fit, in the choice of logistics service providers, enterprise and third-party logistics company is bidirectional, so in line with their own ability level and strategic planning under the premise is especially important to choose the right partner, and the first level is a standard business considerations. The company to be based are certainly based on their own unique culture, this culture covering all aspects of the company, is also reflected in all aspects of its operations, so choose culturally appropriate partners to reduce unnecessary in the process of cooperation the dispute, to ensure smooth implementation of the project.

Microeconomic factors are IT sector procurement, logistics service providers evaluation system is an important direct reference, but also an important driving force for enterprises to choose partners.

\section{IT industry procurement logistics service provider evaluation system}

The basic principle

IT industry for the procurement of third-party logistics service provider attributes, combined with the rapid development of modern logistics, the rising demand for personalized features, this paper follows a systematic, scientific feasibility and practicability of principle, choose a highly 
representative of the eigenvalues IT industry indicators constitute procurement logistics service provider evaluation system.

(1)Systemic

Evaluation Index System Factors to consider all aspects of the comprehensive, all-round, multi-angle reaction procurement logistics service provider level, at the same time, to the close integration system and the target company in order to fully reflect the level of systematic evaluation the pros and cons of the object.

When building the system, consider the factors of time to focus on a comprehensive, avoid duplication and redundancy that would make the final result bias.

(2)Scientific feasibility

IT industry procurement logistics service provider selection problem is the choice of third-party logistics service provider with industry-specific issues, the full attention of industry characteristics, based on the reference and reference materials and other methods simultaneously, to target specific analysis and object accurately reflect the actual situation of logistics service providers.

At the right on the basis of scientific theory, eliminate man-made interference, will index system to quantify the results thus obtained are representative only. Therefore, we must pay attention to the scientific feasibility of the system.

(3)Practicability

Selection of third-party logistics service providers can actually have a number of models, there are many ways, therefore, based on the characteristics of the industry consider the most practical choice of indicators and evaluation methods will reduce a lot of unnecessary steps enterprises, thereby improve efficiency, reduce spending, it is necessary to consider the principle of the system.

\section{Evaluation system}

Based on the above analysis, our IT industry procurement logistics service provider evaluation system into operational level, service level, the level of resources, the level of cooperation and the level of information.

The level of business including price, quality, inventory management, transportation and warehousing four parts. For procurement, logistics service providers, its function is to assume primary responsibility for the service, competent various aspects of the role of logistics is a very important measure.

Service level is an enterprise inventory availability, degree of completion of logistics tasks, flexibility and reliability.

The level of resources refers to the material elements of domination capabilities, including five-part scale, technological innovation, talent, market conditions, equipment installed.

The level of cooperation is mainly fit assessment standard logistics service providers and enterprises, although relatively difficult to quantify the part, but also logistics service providers evaluation system is an important part of this includes corporate reputation, past collaboration experience.

The level of information is the modern IT industry, procurement, logistics service providers an important tool for the integration of resources and the exchange of information, the modern enterprise in constructing its own supply chain system, we need to adopt ERP, supplier management, information systems, not only determines the level of information the company's work efficiency, but also reflect the company's competitiveness, and therefore the level of information in the IT industry, procurement, logistics service providers in the evaluation system is 
also an important link. Here will be divided into information sharing and platform construction in two ways.

\section{Conclusions}

The end result is still the main provider of choice in this article, but the difference is that the object of study is more detailed IT procurement, logistics, this chapter is to introduce the modern IT industry procurement logistics service provider evaluation system. For the first analysis of the status quo to make people understand the current challenges the entire IT industry facing procurement logistics, so the establishment of a reasonable indicator system is necessary. Then from the macro and micro levels to analyze the impact of this factor index system, in a scientific and rational principles to establish a complete IT industry procurement logistics service provider evaluation system to determine the operational level, the level of resources, the level of cooperation, the level of information and service levels of the five main indicators, ready for input and output vectors of later models.

\section{Corresponding Author}

Xin Li, 14120853@bjtu.edu.cn, 15811244288

\section{References}

[1] Dickson,DW. An analysis of vendor selection systems and decision[J].Journal of purchasing,1966,2(1):5-17.

[2] Dennis W.Krumwiede,Chwen Shell. A model for reverse logistics entry bythird-party providers[J] Omega. 2002(30): 325-333.

[3] Srinivas Talluri,Ram Narasimhan. Vendor evaluation with performancvariability:A max-min approach[J]European journal of operational research 2003,146(3)543-552. 